\title{
A snapshot of teachers' knowledge and teaching behaviour with regard to developing self-regulated learning
}

\section{Bernadette Geduld}

Curriculum Studies, Research Focus Area Self-Directed Learning, North-West University, Potchefstroom, South Africa

bernadette.geduld@nwu.ac.za

https://orcid.org/0000-0003-2050-8541

(Received: 19 February 2019; accepted: 3 October 2019)

\section{Abstract}

In the persisting South African education crisis, low quintile schools are known for their lack of adequate resources, poorly trained teachers who lack content and pedagogical knowledge, overcrowded classrooms, and a lack of parental support. I used a qualitative, exploratory, descriptive design to explore South African low quintile school teachers' knowledge of self-regulated learning as well as their perceptions of how they develop self-regulated learning in learners. I conducted semi-structured interviews with 10 purposively and conveniently selected Grade 8 secondary school teachers. The participants hold positive beliefs about self-regulated learning but lack pedagogical knowledge to develop this. They also experience departmental pressure regarding curriculum coverage, assessment, and administration that inhibits their time to do so. The participants perceive their efforts to develop self-regulated learning as being weighed down because this is not a priority at school, with high pass rates in the Annual National Assessment and Senior Secondary School Certificate examinations taking precedence. Future research needs more classroom-based studies to determine how teachers might start to become more skilful at teaching self-regulated learning skills since the development of this is not an automatic process but needs to be supported in learners.

Keywords: metacognition, learners' self-regulation, teacher behaviour, teacher knowledge

\section{Introduction}

Self-regulated learning (SRL) is a strategy to equip learners with life-changing knowledge and skills, so development of this is crucial. SRL is defined as self-generated thoughts, feelings, and actions that are planned and cyclically adapted to the attainment of personal goals (Zimmerman, 2000). SRL describes how learners consciously take responsibility for their own learning by regulating their cognitive strategies, metacognition, motivation, and environment (Pintrich, 2002).

SRL in school environments increases success in problem solving, academic achievement, intrinsic motivation, and task interest as Cleary and Zimmerman (2004) have reminded us. 
Many other researchers (see Bandura, 2006; Moylan, 2013; Zimmerman, 2002) have reported on the value and necessity of SRL in educational as well as social life, and even beyond. All the SRL skills needed for academic achievement, such as planning, goal setting, task analysis, and self-evaluation are also needed if one is to function efficiently in life. Since SRL skills are teachable as Zimmerman (2002) has pointed out, teachers play a vital role in developing and enhancing these. This is particularly important in the South African educational context in which many learners struggle with the demands of the school system.

This study focused on SRL development of Grade 8 learners in two low quintile schools. These schools are in the historically disadvantaged and lower socioeconomic section of the education system and do not charge school fees.

I decided to explore the development of SRL in low quintile schools since these schools are known for their lack of adequate resources, poorly trained teachers who lack content and pedagogical knowledge, overcrowded classrooms, and a lack of parental support (Modisaotsile, 2012). These adversities result in many low quintile schools still underperforming and failing to equip learners with the required knowledge, skills, and values to function effectively in the 21st century as a result of schools in poorer communities still lacking minimum standards because of infrastructure backlogs, textbooks not being delivered on time, and teachers being neither motivated nor supported in their profession, as Spaull (2013) has noted.

I chose Grade 8 teachers as participants since they teach the learners in the first grade of secondary school. At this stage, the learners do not have subject choices; this made the investigation across different subjects taught less complicated. In addition, many Grade 8 learners might not have well developed SRL skills when they enter secondary school, which makes Grade 8 an ideal grade at which to explore the extent to which SRL is developed or not. Zimmerman (2002), for example, reported that many learners in the US appear to have too few learning skills in place when they arrive in secondary school. However, they seldom receive instruction in methods of study or self-regulatory skills in secondary schools. Consequently, there and in South Africa, in the absence of assistance, guidance, or exposure, many learners never acquire SRL skills and this results in a drop in their academic achievement. Although learners learn SRL skills at home, in primary school, or in other places (Zimmerman, 2002), those who are less self-regulated and do not develop SRL skills may experience problems with academic success. In the South African low quintile school context, learners have less exposure to SRL because many of these learners do not have parents or other knowledgeable persons who model SRL for them (Geduld, 2017).

I suggest that underperformance could be alleviated, and higher pass rates achieved if teachers become aware of the value of SRL and how it could help learners to cope with academic as well as other challenges. My contention is supported by the findings of Moylan (2013) and Mutweleli (2014), who have said that SRL is significant for the development of lifelong learning and that it plays a vital role globally in academic learning. Furthermore, these scholars argue that if schools and teachers do not play an active role in the development 
of SRL skills, many learners will struggle with the demands of the school system and of their future lives.

Against the above background of SRL in relation to low quintile schools, I ask three research questions in this study.

- "What knowledge of SRL do the Grade 8 teachers have?"

- "How do Grade 8 teachers perceive their teaching behaviour with regard to developing learners' SRL?"

- "How can SRL be introduced in teaching and learning in low quintile schools to support education in South Africa?"

Increased interest in the development of SRL is based on diverse schools needing to implement 21 st-century competencies to prepare learners for a rapidly changing world, as well as in the interest of social, informational, and technological changes (Cleary \& Zimmerman, 2004; van der Elst, 2016). Eyre (2016) has averred that the focus of teaching should be on developing not only study methods in learners, but also on different problemsolving, metacognitive, and behavioural skills such as being able to take personal initiative, persevere, and be adaptive as well as develop appropriate values and positive attitudes that could better prepare them for a rapidly changing world.

In what follows, I offer, first, the background and orientation of the study, after which I present its conceptual framework, followed by notes on the methodology I used and a discussion of the results of the study. I then provide possible strategies for the development of SRL based on the results of the study before I conclude and offer future directions for research.

\section{The South African education crisis}

One of the three main priorities of the South African National Development Plan (2012) is to improve the quality of education and skills development, along with addressing the education crisis in the country. The persistent challenges to education and the consequences of their not being met are discussed widely in the literature and in government reports (see Mlachila \& Moeletsi, 2019; Spaull \& Kotze, 2015; Stott, 2018.) Roodt (2018) has identified teachers' poor pedagogical content knowledge as a challenge and a reason behind the underperformance of learners. He has pointed out, furthermore, that international rankings such as the Trends in International Mathematics and Science Study (TIMMS) as well as the Progress in International Reading Literacy Study (PIRLS) have revealed that South African learners performed poorly in mathematics, science, and literacy compared to their international counterparts (see also Mlachila \& Moeletsi, 2019).

With so many serious issues in the education sector that need to be remedied, one might wonder why the development of SRL is significant. I hope that the findings of this research will stimulate discussions with teachers about the position, importance, and usefulness of SRL and envision it changing teaching behaviour in ways that will improve the academic 
performance of the learners. Teachers' knowledge of SRL (or the lack of it) and their perceptions about their teaching behaviour provide an explanation for the occurrence (or absence) of SRL practices in South African low quintile schools. The findings of the study might also serve as an instrument for reflection and offer some ideas for changing practice.

\section{Conceptual framework}

The social-cognitive perspective maintains that SRL is influenced by personal, environmental, and behavioural determinants (Schunk, Pintrich, \& Meece, 2014). In this model of triadic reciprocality, the three determinants interact with one another as Bandura (2006) has reminded us. Changes in one determinant result in changes in one or two other determinants. Personal determinants represent, particularly in this study, participants' teacher training, pedagogical knowledge of SRL, along with thoughts, feelings, beliefs, and other motivational forces that enable them to develop SRL skills in themselves and in learners. Environment determinants refer to social and physical factors and contexts that can affect an individual's behaviour. In this study, these include learners, parents, colleagues, the physical size of classrooms, and the dictates of the Departments of Education, all of which contribute to the social and physical working environment of teachers. Behavioural determinants refer to participants' teaching strategies, their choice of tasks, and their efforts to develop learners' SRL skills.

When it comes to teachers' behaviour in the development of SRL, Zimmerman (2001, p. 8) asked five questions. "How do teachers motivate learners to be self-regulated? How do they make learners aware of their self-regulation? How do teachers help learners to achieve academic goals? How do teachers adapt the social and physical class environment to influence SRL? How do teachers monitor learners' SRL development?" In answering these questions, the personal, environmental, and behavioural determinants that influence how low quintile school teachers develop learners' SRL should be taken into account.

Dignath-van Ewijk and van der Werf (2012) explain that teachers' ability to teach SRL or teach through SRL is influenced by their pedagogical knowledge as well as their beliefs about learner-centred learning. Moreover, teachers' knowledge and beliefs influence their perceptions, which, in turn, evoke behaviour that is consistent with these beliefs and this, consequently, influences their teaching behaviour.

Research on teachers' knowledge of SRL, as well as their perceptions and beliefs about, and their teaching behaviour in relation to developing SRL, indicates that the concept of selfregulated learning is vague and unclear for many of them (Dignath-van Ewijk \& van der Werf, 2012). Despite their positive beliefs regarding SRL, teachers, especially inexperienced ones, do not have a broad knowledge of how to foster SRL. Peeters, De Backer, Reina, Kindekens, Buffel, and Lombaerts (2014) have noted that, although teachers generally accept the important role they play in learners' self-regulatory activities, they often do not know how to teach self-regulatory skills or how to otherwise enhance learners' use of selfregulation principles in the classroom or other learning settings. This lack of knowledge 
stems from several sources such as teachers' educational beliefs as well as teacher education programmes that typically emphasise content-area knowledge and mastery of pedagogical methods, and focus less on principles of learning, development, and motivation.

Furthermore, Lau (2013) has found that teachers' behaviour is not only influenced by their knowledge and beliefs but also by external factors such as the school and class variables and features of the subject content. Notwithstanding the above findings, many examples of teaching behaviour that promotes the development of SRL are prominent in the literature. For example, Schunk et al. (2014) have stated that teachers should give learners choices, opportunities to control challenges and to evaluate their own and peers' learning, along with instrumental support, scaffolding, feedback, and evaluation that is nonthreatening and mastery oriented. Paris and Paris (2003) emphasised that learners are more likely to become self-regulated when they are able to evaluate their own learning, independently of teacherissued summative assessments. Self-evaluation enables learners to evaluate their comprehension of the learning content and learning strategies and make adjustments for similar tasks in the future. Furthermore, as Radel, Sarrazin, Legrain, and Wild (2010) and Schunk et al. (2014) have shown, learners are more likely to attend to and imitate the actions of competent and intrinsically motivated teachers who facilitate SRL, as opposed to teachers who seem less competent.

To promote SRL in classrooms, teachers should teach learners self-regulated processes, such as proximal and distant goal setting, planning, task analysis, and time management (Winne \& Hadwin, 1998). Paris and Paris (2003) suggested that teachers should model how to use new strategies and provide suitable scaffolding as the learners practise these. Zimmerman (2002) noted that teachers should prepare their learners to take ownership of their learning and develop their ability to control how, where, what, and when they study. Schunk and Pajares (2009) have emphasised high self-efficacy beliefs that lead to increased motivation to set better goals, make more effort to analyse tasks, and plan and use self-regulation strategies, which, in turn, could lead to better academic achievement.

Cooperative learning and peer learning, according to Pritchard (2009), develop SRL because of the social and active learning processes during which learners use collaboration and interaction as a strategy to share ideas, clarify uncertainties, and learn from one another. Another advantage is that with social support in cooperative and peer learning, learners learn to take personal initiative, to endure, and to adjust their strategies when they seek help from peers and experts (Schunk et al., 2014). According to Dede (2010) cooperative learning prepares learners for four essential 21st-century skills: collaborating with others; understanding and communicating ideas; thinking critically; and producing quality work.

\section{Methodology}

I was guided by an interpretivist paradigm in order to explore Grade 8 teachers' knowledge of, and teaching behaviour in relation to, SRL in low quintile schools. Because of the philosophical assumptions and investigative nature thereof, I deemed an interpretivist 
paradigm suitable for this research that sought to explore a contemporary phenomenon in a real-life situation. Using this qualitative research design, following Maree (2016) I attempted to collect rich descriptive data, with the intention of developing an understanding of the participants' knowledge and teaching behaviour in relation to SRL in two low quintile schools.

\section{Research setting and sampling}

I conducted the study in two low quintile schools in the Eastern Cape Province of South Africa that admit learners from Grade 8 to 12. School A was previously perceived as an underperforming school but improved and had Grade 12 pass rates of $87 \%$ in 2017 and $78.9 \%$ in 2018. School B was still perceived by the community as a declining school because of the falling Grade 12 results which dropped to $50 \%$ in 2015, but it has also improved in achieving a Grade 12 pass rate of $63.3 \%$ in 2016 and $69.8 \%$ in 2017.

The sites were conveniently selected because the participants were able and willing to share their knowledge of SRL and how they developed SRL in their learners. The schools have adequate infrastructure for teaching and learning, but the classrooms in School A are overcrowded and the learners have to share desks and books. School A has predominantly Afrikaans-speaking learners, and the medium of instruction is Afrikaans and English. School B has predominantly isiXhosa-speaking learners, and the medium of instruction is English and isiXhosa.

I used purposive sampling to select five Grade 8 teachers from each school, based on their first-hand experience of teaching Grade 8 learners. The sample consisted of six female and four male participants, with teaching experience that ranged between one and thirty years. Eight participants had degrees, and two participants had advanced diplomas in education. All the participants taught the subjects in which they had specialised, except for Participant 1.

Ethical clearance was obtained from the university. I abided by all ethical aspects of conducting research, such as obtaining permission from the Department of Basic Education and informed consent from the participants, demonstrating respect for the participants, and upholding confidentiality and anonymity.

\section{Data collection}

Data was collected via semi-structured individual interviews. My using open-ended questions in these interviews enabled the participants to give detailed answers, explanations, and interesting information, all of which helped in the thematic analysis of the data as advocated by Maree (2016). The semi-structured interviews provided useful information and gave me better control over the type of information I received since I could ask additional questions to elicit information on a specific topic. An explanation of the concept of SRL was given when a participant did not have any knowledge or an erroneous understanding of the concept. I asked these broad questions in the semi-structured interviews, which lasted 30 to 40 minutes.

- "What do you know about the concept of self-regulated learning (SRL)?" 
- "How do you develop SRL in your learners when you teach?"

\section{Data analysis}

The voice recordings of the interviews were transcribed verbatim, and the resulting texts were analysed by means of content and thematic analysis. Following Saldaña (2015), I used codes derived from the literature to categorise the responses referring to teaching behaviour that develops learners' SRL. The reciprocal interactions among personal, behavioural, and environmental determinants of participants' knowledge and teaching behaviours in developing SRL were also analysed. I developed nine themes from the literature on SRL: (1) knowledge of SRL; (2) physical classroom environment and lesson presentation; (3) modelling of learning strategies; (4) goal setting, planning, and time management; (5) developing self-evaluation; (6) responsibility for own learning; (7) motivation and selfefficacy; (8) cooperative learning; and (9) contextual constraints to developing SRL.

\section{Trustworthiness}

The validity of the study is supported by describing the findings in rich detail, with verbatim quotations so that readers can draw their own conclusions from the data presented. Furthermore, I consulted with colleagues in the field who agreed that appropriate interpretations had been made and valid conclusions had been drawn from the data.

\section{Results and findings}

The first theme answers the first research question and describes the participants' knowledge of SRL.

\section{Knowledge of SRL}

Three participants indicated that they came across the concept of SRL when they were improving their qualifications. One participant said,

One person mentioned it in a maths workshop I attended at the Stellenbosch University. To me, it is a question of learners being the initiators of learning where you do not spoon-feed them. Learners taking responsibility for their learning, and educators are there to guide them. (P4)

Five other participants said that the concept had been introduced to them in their teacher training. They understood it and knew it by other names such as expert learning, strategic learning, independent learning, or "lifelong learning."

To another participant, whose teacher training had been completed 17 years ago, the concept was vague and unclear. 
I have never heard about self-regulated learning. In my initial teacher training, we were trained more on content knowledge and the application thereof. We never really focused on developing learners to become independent learners. (P10)

This extract supports the findings of Peeters et al. (2014), mentioned above, that teachers lack the knowledge and skills to develop SRL because teacher education programmes usually emphasise content-area knowledge and mastery of pedagogical methods.

This theme revealed that participants' personal determinants such as their knowledge of SRL, training in traditional transmission teaching methods, their continual teacher training, and their pedagogical knowledge, as well as the lack thereof in some cases, constituted the behavioural determinant that influenced their teaching behaviour and their level of ability to develop self-regulated learning in their learners. Teachers in low quintile schools are generally labelled as having insufficient content-area and pedagogical knowledge, so it was surprising that most of the participants were familiar with the concept of SRL. Contrary to popular belief about such teachers, the participants in this study seemed passionate about the teaching profession and their responsibility to develop holistic learners. They had vague explanations of the concept of SRL, but they could connect the concept to expert learning, strategic learning, and lifelong learning.

The following eight themes indicate the participants' perceptions of their teaching behaviour in relation to developing SRL.

\section{Physical environment of classes and presentation of lessons}

The participants' responses indicated that they used the social and physical environment of their classrooms to create a setting that was conducive to learning and SRL and therefore met expectations for learning. Two participants perceived a well-prepared lesson, presented in a clean classroom with posters and other resource material, as creating an ideal atmosphere for learning and as being conducive to developing SRL. It is evident that the interaction between these two participants' personal and behavioural determinants influenced their environment determinants, which resulted in the creation of social and physical class environments that fostered the development of SRL skills. They said, respectively,

The development of SRL starts with the teachers' lesson presentation. If the lesson is interesting, learners will want to learn and will want to achieve. The teacher motivates learners with his or her subject knowledge and passion for the subject. (P4)

I keep their learning styles in mind. I bring my radio when I do marketing; learners are more interested then. I do drama and role play in the marketing lesson with learners. It stimulates them. (P3)

The theme revealed that the participants believed in traditional teaching that emphasises that competent teachers with subject knowledge should present interesting lessons. The implications are that teachers with such views will raise learners' task interest and the intrinsic value of learning, both important SRL processes (see Radel et al., 2010). It is 
noteworthy that only two participants mentioned the value of classrooms that are conducive to learning, even though we know that the learning environment teachers create in their classrooms affects the degree of learners' motivation to be at school and their engagement in learning. The participants' ignorance about the value and effects of creating a classroom environment that would foster the development of SRL might stem from their lack of pedagogical knowledge of classroom management. This lack in the eight other participants was the personal determinant that influenced their behaviour determinant that is, the inability to create classrooms conducive to learning, which led, in turn, to their environment determinant that is, classrooms that are boring (see Lau, 2013).

\section{Modelling of learning strategies}

This theme revealed that, in line with other research, the participants used cognitive strategies such as repetition, elaboration, questioning, summarising, and activating prior knowledge to develop SRL. Other strategies mentioned by Paris and Paris (2003), such as step-by-step explanations and modelling in combination with direct teaching, were also mentioned by the participants.

It was interesting to note that many participants could not describe how they specifically integrated metacognitive and reflection strategies, such as self-questioning and monitoring comprehension and progress in their teaching. This is another example of how personal determinants (in this case, participants' lack of pedagogical knowledge) influenced their teaching behaviour aimed at creating a learning environment that fosters the development of different learning strategies. One participant indicated that he taught his learners imagery as a strategy, as well as where and how to find resources and another stressed the importance of making summaries.

I teach them to visualise the things they are learning about. I give many practical examples. I always try to get my learners [to be] inquisitive. I use direct teaching, step-by-step explanations, guided practice, and many practical examples and let them give examples too. I give my learners still a lot of guidance, for example where to find resources they need. (P4)

I tell them to make summaries and I look at [them] the next day. (P7)

\section{Goal setting, planning, and time management}

From the limited responses of how the participants developed goal setting, planning, task analysis, and time management, it could be concluded that these aspects of SRL had been neglected in most of the participants' teaching behaviour. Similar to the three themes just discussed, the personal-behaviour-environment interactions of participants exemplify, in line with Lau's (2013) findings, how their lack of pedagogical knowledge to develop SRL skills can influence their teaching behaviour.

The following responses reflect the typical approaches adopted by the participants. 
I show them in advance how the question paper will be set, the different sections, how much time they must use for the specific mark allocations. I teach them to manage their time. I give them examples of how the same content can be asked in different questions. I guide them on how to set personal goals and to keep up high standards to master all the content. Right in the front of their books, they have to write the percentage they want to have at the end of the year in the subject. (P2)

I talk to them about their future dreams, what they want to become. As soon as they know it is possible, what the requirements are, they will work hard to achieve it. (P9)

This theme revealed that the participants used verbalisation, intrinsic and mostly extrinsic motivation, as well as positive outcome expectations as mechanisms to teach learners to set proximal and distant goals. A few participants mentioned goal setting to a lesser extent, but no references were made to planning and task analysis, which are closely related to goal setting. If goal setting, planning, and time management were integrated into teaching strategies to develop SRL, the objectives of the lessons would be clear, learner motivation would improve, learners would stay on-task, and they would be more likely to engage in selfregulation as Schunk et al. (2014) have pointed out. The participants perceived the importance of time management as more related to summative examinations and not to everyday planning of study time and leisure time. In general, the participants' teaching behaviour did not reflect goal setting, planning, and time management as priority strategies to develop SRL.

\section{Developing self-evaluation}

The participants' teaching behaviour in relation to developing SRL through self-evaluation supports the research of Lau (2013), mentioned above. The participants mostly embedded self-evaluation and formative assessment by frequently setting short tests. Participants 1, 2, 4, and 8 used short tests for learners to self-assess and peer-assess their progress and to learn from their mistakes. Such use of self-evaluation enables learners to learn from feedback and to take responsibility for their own learning. It also reduces anxiety, and errors made are regarded as opportunities to improve. These practices, as described by the participants, give learners the opportunity to reflect on and judge their own understanding and progress in relation to the qualities they, the teachers, and in some cases, the group as well, identify as high-quality work. The following responses summarise the views of most of the participants.

I give tests every second week so that they can learn to self-evaluate their understanding and reflect [on] how they will do better the next week. (P4)

After tests, I also let the clever ones explain to those who struggle in isiXhosa on the writing board at the back of the class. They learn quicker if it is explained in their home language. $(\mathrm{P} 2)$

Similarly to the previous one, this theme revealed that the participants' teaching behaviour is influenced by personal determinants such as pedagogical knowledge of teacher centered 
methods of drill, practice and questioning (Dignath-van Ewijk \& van der Werf, 2012). On the one hand, the contradictory nature of questioning, repetition, and testing is that it is teacherdirected. It imposes a sense of teacher control, but, on the other hand, it could help learners to monitor and self-regulate their behaviour in order to apply themselves to learning and to pass examinations. Constant questioning on different cognitive levels helps learners to return to the main idea of learning and to check their progress. According to Schunk et al. (2014), feedback can develop SRL and lead to the mastery of goal orientation if it communicates that these mistakes are part of learning, and if learners' efforts are recognised.

\section{Responsibility for own learning}

It is remarkable that the participants perceived homework as the only strategy they applied to help learners develop taking responsibility for their own learning. This strategy supports the views of Paris and Paris (2003) that guided practice of content in class should be followed by independent practice in the form of homework. By giving homework to learners, teachers give them opportunities to practise strategies on their own. However, given the influence of personal-behaviour determinants, which can be inferred from most of the participants' personal knowledge and experience on traditional content teaching as Lau (2013) has made clear, it was not surprising that they had difficulty in explaining how learners were being encouraged to take responsibility for their own learning besides by completing homework.

In the context of the education crisis that is characterised by, among other things, underresourced schools in which learners have to share books in class, the question about how learners complete their homework without books arises. One school in the study is poorly resourced in terms of textbooks, which is problematic, especially in cases where teachers, because of poor pedagogical and content knowledge, rely on textbooks. The National Planning Commission (2012) reported that many South African teachers have insufficient content and pedagogical knowledge. This raises the question of whether teachers in schools with insufficient textbooks and teaching and learning aids have the ability to use any other common, free, or cheap everyday objects to assist with concept development in their subjects. In addition, the shortage of textbooks has implications for homework activities, especially in the socioeconomic context of learners in low quintile schools who come from poor households where the stimulation of reading and any other study material are non-existent.

This is what three participants had to say.

You just give your lesson, explain what they must do, then give their homework. They must learn to work on their own and be accountable for their wrongdoings if they did not do the homework. (P8)

I give them choices of study methods. Learners take responsibility for their learning when they write the summaries down and study at home. I also give them homework. (P5) 
I let them go to the library to find information to work on the internet and to produce good projects. (P9)

\section{Developing motivation and self-efficacy}

All the participants perceived their teaching behaviour to be geared towards the expansion of motivation, confidence, and self-efficacy to develop learners' SRL. This comment summarises the participants' overall perceptions of their teaching behaviour regarding motivation and self-efficacy.

I work hard to get the learners motivated. I tell them to persist in difficult times. I have expectations for their success. I support my learners academically and emotionally. (P3)

From the participants' responses, it can be concluded that the fact that they perceive themselves as role models (personal determinants) influences their teaching behaviour (behaviour determinant). Therefore, they claim to teach learners to develop effort and persistence, which are both characteristics of self-regulated learners. This finding supports similar findings of Schunk et al. (2014), who noted that motivational processes, such as having expectations and emotions, and making attributions help learners to overcome difficulties and sustain motivation. All the participants perceived themselves as role models who were developing motivation, self-efficacy, and outcome expectations in their learners. Their commitment to developing motivational beliefs might stem from their own experiences since all the participants had received their primary and secondary school education in low quintile schools and indicated that education was the one factor that had changed their lives.

In light of the education crisis in South Africa and the resulting high dropout and failure rates, these strategies of the participants to build positive self-motivational beliefs are indispensable. It is especially relevant for learners from poor socioeconomic backgrounds, where parental support and interest in learners' academic work are often absent since poverty might prevent parents from focusing on anything beyond the most urgent daily needs of the family (Malebese, 2013).

\section{Cooperative learning}

Despite the advantages of developing SRL through cooperative learning, only three participants could explain how they used cooperative learning to develop SRL. The following responses encapsulate the reluctance of three other participants to use cooperative learning as a strategy to do so.

I am not pro group work. I want to see the individual learner's ability. There are many social circumstances to consider if you give group projects. Not all learners have transport or money to meet the group at the library. Many learners have to do cooking and cleaning after school. (P8) 
I never do group work in class; it is too difficult with a class of 48 to 50 learners. (P10)

The shortage of desks and books makes group work a challenge, and passive learners get lost. It only works to a certain extent. (P3)

From the participants' hesitancy about, and antagonism towards, cooperative learning, I concluded that they did not perceive this to be a strategy in developing SRL. The contextual complexities, such as poor infrastructure, insufficient books and benches, and overcrowded classrooms of this particular group of participants from low quintile schools, clearly influenced their beliefs and teaching behaviour.

\section{Contextual constraints to developing SRL}

In line with the findings of Lau (2013), the participants identified factors that affected their beliefs about and behaviour regarding developing SRL. The strategies of the Department of Basic Education to monitor differing compliance with the implementation of the curriculum, assessment, improved results, governance, and management seemed to have demotivating effects on these participants. Although they indicated that they held positive beliefs about SRL, I detected frustration and helplessness in their responses about departmental pressure regarding coverage of the curriculum, assessment, and administration. The participants perceived their efforts to develop SRL as being weighed down because the development of SRL was not a priority at school, with high pass rates in the Annual National Assessments and Senior Secondary School Certificate examinations taking precedence.

The following responses articulate the views of some of the participants.

The workload that we have, and overcrowded classrooms make it difficult to pay attention to the development of self-regulated learning. We are so under pressure to finish the syllabus because the Department is standing on your neck. (P9)

The school's focus is more on organisation of the school day, invigilating for absent teachers or for classes where teachers have not yet been appointed. I do not think development of learners' SRL is a priority here. The shortage of textbooks is a problem. I cannot even give homework, and there is not money for paper to make worksheets. (P5)

I must focus to complete the syllabus. There are many functions, for example Valentine's Day, fundraisings, and meetings, that influence our teaching time. (P6)

Although most of the participants accepted their responsibility to develop SRL in learners, they did not find it easy to implement such practices without support from the school, community, and parents. Many of the factors identified in this theme are beyond teachers' control and point to insufficient support in terms of resources and human capital from the Department of Basic Education. Paris and Winograd (2003) warn that although most teachers would agree that teaching learners to be more self-regulated in the classroom would be ideal, 
the practice is not simple and does not come without challenges. This finding is supported by Boekaerts and Cascallar (2006), who reported that the major obstacle in helping learners become self-regulated is the time required to teach them how to use specific strategies.

From the perspective of the model of triadic reciprocality (Bandura, 2006), the influence of environmental determinants on personal and behaviour determinants in the last two themes was evident. Environmental determinants such as pressure from the Department of Education, overcrowded classrooms, lack of textbooks and other resources negatively influence participants' personal motivation and beliefs (personal determinant) about the value of developing SRL through learner-centred teaching strategies, which in turn influences their teaching behaviour (behaviour determinant) to develop SRL. These findings are supported by Dignath-van Ewijk and van der Werf (2012), Lau (2013), and Peeters et al. (2014).

\section{How can SRL be developed in low quintile schools?}

Based on the findings of the study, the following strategies, in addition to the strategies mentioned in the conceptual framework, are recommended for teachers to develop SRL in low quintile schools to support education in South Africa.

Modelling is one method through which teachers can develop the setting of goals, planning, time management, and the use of metacognitive monitoring strategies. Schunk and Zimmerman (1996) propose five types of modelling for teachers to develop SRL skills. The first is disposition modelling in which teachers display their own attitudes and dispositions, values, and practices of SRL skills. The second is task and performance modelling, during which learners observe teachers' demonstrations of problems on writing boards, listen to pronunciation in language or reading lessons, or the steps and procedures followed for experiments. With task and performance modelling, teachers should be aware of poor language skills and communication that might restrict comprehension, which could result in misinterpretation and confusion. Teachers should support verbal explanations with visual aids to help, for example, isiXhosa-speaking learners who have a poor command of English, or Afrikaans-speaking learners who have poor English language proficiency. Examples and analogies relevant to learners' cultural backgrounds and life experiences in their communities should be prepared.

The third type, metacognitive monitoring, is promoted when teachers activate learners' prior knowledge, use elaboration and imagery, explain their own thought processes verbally, and explain how they apply SRL skills, such as planning, goal setting, self-questioning, and so forth while they are solving a problem (Paris \& Paris, 2003). Probing, and asking open-ended questions that promote discussion among learners help to develop SRL skills such as reflection, self-questioning, and monitoring of comprehension and progress (Paris \& Paris, 2003). Learners' answers should receive different types of feedback. For example, individualised, interrogative feedback on the resources and metacognitive skills applied, could be offered. 
The fourth type is modelling as a scaffolding technique, which could be useful for struggling learners in low quintile schools. The last type is learner-centred modelling, whereby learners are assisted to learn particular concepts from the modelling of more expert peers (Schunk \& Zimmerman, 1996).

To develop learners' responsibility for their own learning, teachers should ensure that the elements that contribute to learner agency are being incorporated into their teaching. These elements include engaging learners by giving them a voice in the learning process, giving them choices, ownership, a purpose for learning, motivation, and positive self-efficacy beliefs (Bray \& McClaskey, 2016). Although the type of classwork and homework to be done remains the teacher's responsibility, I recommend the strategies of Schunk et al. (2014). These strategies, suitable as they are for teachers in low quintile schools, such as allowing learners opportunities for leadership roles and the development of a sense of independence and control over learning activities could result in learners taking more responsibility for their own learning. To ensure this, teachers should design multiple, interesting, and novel tasks on the same topic and allow learners to choose a specific task that is of interest to them. In addition, they could be allowed to choose their own study partners and make decisions on how, when, and where tasks should be completed. Discussions with learners about a reasonable pace and time for the completion of tasks could develop time-management skills as Schunk et al. (2014) have indicated. In light of the poor socioeconomic situation of many learners in low quintile schools, learners should be encouraged to discuss any home or financial constraints that prevent them from completing homework. In such cases, teachers should arrange other venues where learners can complete home-based tasks.

Teachers need to consider how they could optimise and extend the classroom space to incorporate learner-centred teaching methods, such as cooperative learning. They could, for example, make adjustments in their classrooms by rearranging the desks and chairs. On days when cooperative learning tasks are planned, the restrictive classroom space could be extended outdoors to the school grounds (weather permitting) or to empty classrooms available at the school. The teacher's classroom could then be used only as the meeting place where the groups present their findings and the teacher concludes the lesson as Mays, Grosser, and de Jager (2016) have suggested. Cooperative learning methods, such as more problem-based and discovery activities, could take place outside the classroom.

Teachers should consider the use of other sources and materials to supplement textbooks. The lack of physical learning resources, such as books, could be overcome by dividing learners into small groups, which allows the use of only one book or answer sheet, or other resources (see Mays et al., 2016). For class-based teaching, teachers could design tasks that combine small-group activities with reading, discussion of ideas, and listening, which develop problem-solving and thinking skills. Teachers should ensure that the resources the learners would need are available.

Even though textbooks and workbooks are seen to be core learning resources in schools, teachers should become more resourceful in their use of educational resources. They could, for example, employ simple non-educational ones (tins, cardboard pieces, etc.) or the media 
(newspapers, advertising pamphlets, fast-food menus, etc.) to promote learning. Moreover, many downloadable digital resources available on the internet, resources found in the learners' local environment, and learners' own life experiences and knowledge could be used fruitfully in learning tasks that develop SRL (Mays et al., 2016). Given the education crisis in terms of dropout and underperformance, this is one way in which teachers could create classrooms that are conducive to learning and teaching with ordinary resources to develop learner interest and motivation to learn. The use of such resources to enrich the physical environment of their classrooms would positively influence SRL skills such as motivation, focusing attention, and task interest (Schunk et al., 2014).

Finally, I suggest that teachers should initiate strategies to bring the parents at low quintile schools to the education table. They could start by contacting parents through home visits, newsletters, or phone calls to create awareness of the benefits of parental involvement. Guidelines could be given to show parents how they could develop and enhance SRL by engaging their children in cognitively stimulating activities at home by offering motivational and emotional support for homework activities, and by creating stable environments that are conducive to learning for home-based learning activities.

\section{Conclusion and future directions}

This study offers a snapshot of how the reciprocal interaction of personal behaviour, and environmental determinants in two low quintile schools influence teachers' perceptions on developing SRL skills in their Grade 8 learners. From the results, it is evident that some persisting causes of the education crisis, as mentioned by the National Planning Commission (2012), are not being addressed in these two low quintile schools. The participants in the study mentioned frustrating factors that inhibit them from developing SRL skills that prepare learners for the demands of the 21 st century. These factors include an overload of assessment administration, the interruption of teaching time, an increased workload because of the shortage of teachers, a demanding curriculum that puts pressure on them to complete the syllabus, social and environment influences, overcrowded classrooms, insufficient textbooks, and a lack of resources. It is alarming that the vast majority of SRL skills, which are part of the general aims of the Curriculum Assessment Policy Statement, are not being developed by the participants, partly because of a lack of pedagogical knowledge.

This study was subject to some limitations. The sample does not allow for the generalisation of the participants' knowledge of and behaviour regarding SRL in low quintile schools to secondary schools at large.

Future research needs more classroom-based studies to determine how teachers could start to become more skilful in teaching SRL skills. It is essential that the teachers who participated in the study recognise the need to become motivated and change their teaching practices. School-based learning and professional development with continual support and monitoring are recommended. Contextualised pedagogical training for teachers at low quintile schools with similar challenges and needs to help them address the development of SRL and other 
21 st-century skills should be offered. Fundamental changes at school level need to occur for teachers to be able to allocate the time and resources necessary for helping learners to become self-regulated. The curriculum and accompanying assessment systems must be organised in ways that support and value SRL.

\section{References}

Bandura, A. (2006). Toward a psychology of human agency. Perspectives on Psychological Science, 1 (2), 164-180. http://doi.org/10.1111\%2Fj.1745-6916.2006.00011.x

Boekaerts, M., \& Cascallar, E. (2006). How far have we moved toward the integration of theory and practice in self-regulation? Educational Psychology Review, 18(3), 199210. http://doi.org/10.1007/s10648-006-9013-4

Bray, B., \& McClaskey, K. (2016). How to personalize learning: A practical guide for getting started and going deeper. Thousand Oaks, CA: Corwin Press.

Cleary, T. J., \& Zimmerman, B. J. (2004). Self-regulation empowerment program: A schoolbased program to enhance self-regulated and self-motivated cycles of student learning. Psychology in the Schools, 41(5), 537-550. http://doi.org/ 10.1002/pits. 10177

Dede, C. (2010). Comparing frameworks for 21 st-century skills. In J. Bellanca \& R. Brandt (Eds.), 21 st century skills: Rethinking how students learn (pp. 51-75). Bloomington, IN: Solution Tree Press.

Dignath-van Ewijk, C., \& van der Werf, G. (2012). What teachers think about self-regulated learning: Investigating teacher beliefs and teacher behavior of enhancing students' self-regulation. Education Research International. http://doi.org/10.1155/2012/741713

Eyre, D. (2016). High performance learning: How to become a world class school. New York, NY: Routledge.

Geduld, B. W. (2017). Personal and contextual influences on low-quintile school learners' motivation and self-regulated learning. African Education Review, 14(3), 1-18.

Lau, K. L. (2013). Chinese language teachers' perceptions and implementation of selfregulated learning-based instruction. Teaching and Teacher Education, 31(1), 56-66. http://doi.org/10.1016/j.tate.2012.12.001

Malebese, M. L. (2013). The relationship between parental support and self-regulated learning behaviour of Grade 12 learners in Lejweleputswa (Unpublished doctoral dissertation). University of the Free State, Bloemfontein, RSA.

Maree, K. (2016). First steps in research (11th ed.). Pretoria, RSA: van Schaik. 
Mays, T., Grosser, M., \& de Jager, L. (2016). Getting practical: A guide to teaching and learning. Cape Town, RSA: Oxford University Press.

Mlachila, M. M., \& Moeletsi, T. (2019). Struggling to make the grade: A review of the causes and consequences of the weak outcomes of South Africa's education system. International Monetary Fund Working Paper No. 19/47.

Modisaotsile, B. M. (2012). The failing standard of basic education in South Africa. Policy brief. Africa Institute of South Africa, 72, 1-7.

Moylan, A. (2013). Cyclical feedback approaches for enhancing academic self-regulation in postsecondary mathematics classrooms. In H. Bembenutty, T. J. Cleary, \& A. Kitsantas (Eds.), Applications of self-regulated learning across diverse disciplines: A tribute to Barry J. Zimmerman (pp. 125-152). Charlotte, NC: Information Age Publishing.

Mutweleli, S. (2014). Academic motivation and self-regulated learning as predictors of academic achievement of students in public secondary schools in Nairobi County, Kenya (Unpublished doctoral dissertation). Kenyatta University, Nairobi, KE.

Paris, S. G., \& Winograd, P. (2003). The role of self-regulated learning in contextual teaching: Principals and practices for teacher preparation. Educational Psychologist, 36(2), 89-101. http://www.ciera.org/library/archive/ 2001- 04/0104prwn.pdf

Peeters, J., De Backer, F., Reina, V. R., Kindekens, A., Buffel, T., \& Lombaerts, K. (2014). The role of teachers' self-regulatory capacities in the implementation of self-regulated learning practices. Procedia-Social and Behavioral Sciences, 116, 1963-1970.

Pintrich, P. R. (2002). The roles of metacognitive knowledge in learning, teaching, and assessing. Theory into Practice, 41(4), 219-225.

Pritchard, A. (2009). Ways of learning: Learning theories and learning styles in the classroom (2nd ed.). New York, NY: David Fulton.

Radel, R., Sarrazin, P., Legrain, P., \& Wild, T. C. (2010). Social contagion of motivation between teacher and student: Analyzing underlying processes. Journal of Educational Psychology, 102(3), 577-587.

Republic of South Africa: National Planning Commission. (2012). National Development Plan 2030: Our future-make it work. Pretoria, RSA: Author. https://www.gov.za > issues > national-development-plan-2030

Roodt, M. (2018). The South African education crisis: Giving power back to the parents. Johannesburg, RSA: The South African Institute of Race Relations. Available at https://irr. org. za/reports/occasionalreports/files/the-south-african-education-crisis31-05-2018.pdf 
Saldaña, J. (2015). The coding manual for qualitative researchers. Los Angeles, CA: Sage.

Schunk D. H., Pintrich P. R., \& Meece, J. L. (2014). Motivation in education: Theory, research, and applications (3rd ed.). Upper Saddle River: NJ: Merrill Prentice Hall.

Schunk, D., \& Pajares, F. (2009). Self-efficacy theory. In K. R. Wentzel \& A. Wigfield (Eds.), Handbook of motivation at school (pp. 35-54). New York, NY: Routledge.

Spaull, N. (2013). South Africa's education crisis. Report for the Centre for Development and Enterprise. Johannesburg, RSA: Centre for Development and Enterprise.

Spaull, N., \& Kotze, J. (2015). Starting behind and staying behind in South Africa: The case of insurmountable learning deficits in mathematics. International Journal of Educational Development, 41, 13-24. http://doi.org/10.1016/j.ijedudev.2015.01.002

Stott, A. E. (2018). Are instructivist pedagogies more appropriate for learning the sciences in South African low-quintile schools than western literature suggests? Journal of Education, 71, 39-57. doi.org/10.17159/2520-9868/i71a03

van der Elst, L. (2016). Innovation in education: Technical report. MIET Africa. National Education Collaboration Trust. https://www.mietafrica.com/wpcontent/uploads/2016/09/Innovation_in_Education_Technical_Report_March_2016.p df

Winne, P. H., \& Hadwin, A. F. (1998). Studying as self-regulated learning. In D. J. Hacker \& J. Dunlosky (Eds.), Metacognition in educational theory and practice. The educational psychology series (pp. 277-304). Mahwah, NJ: Erlbaum.

Zimmerman, B. J. (2000). Attaining self-regulation: A social cognitive perspective. In M. Boekarts, P. R. Pintrich, \& M. Zeidner (Eds.), Handbook of self-regulation (pp. 1339). New York, NY: Academic Press.

Zimmerman, B. J. (2001). Theories of self-regulated learning and academic achievement: An overview and analysis. In B. J. Zimmerman \& D. H. Schunk (Eds.), Self-regulated learning and academic achievement: Theoretical perspectives (2nd ed., pp. 1-37). London, UK: Erlbaum.

Zimmerman, B. J. (2002). Becoming a self-regulated learner: An overview. Theory into Practice, 41(2), 64-70. http://doi.org/ 10.1207/s15430421tip4102_2 